\title{
Successful treatment of nonunion in severe finger injury with low-intensity pulsed ultrasound (LIPUS): a case report
}

\author{
Michaela Huber*, Lukas Prantl and Sebastian Gehmert
}

\begin{abstract}
Introduction: Severe injuries of the hand or single fingers require immediate treatment but surgical fixation methods are limited depending on soft tissue damage. Thus, it is very common that severe soft tissue damage along with poor osteosynthetic bone fixation results in a delayed healing process or nonunion. Low-intensity pulsed ultrasound (LIPUS) has been proven to stimulate bone formation in in vitro studies and also to significantly accelerate nonunion healing in animal studies and clinical trials but to date there are no data with respect to nonunion in phalanx fracture.
\end{abstract}

Case presentation: We report a case in which we successfully used LIPUS in a 19-year-old Caucasian man with a nonunion of his ring finger after injury and first treatment with K-wire osteosynthesis.

Conclusion: We recommend that LIPUS be considered as an option to treat nonunions in fractures of the hand, especially because it is a soft tissue conserving method with a good functional result.

\section{Introduction}

In recent years, low intensity pulsed ultrasound (LIPUS) has been the focus of several studies examining how to help stimulate bone formation in fractures and nonunions [1-3]. However, to the best of our knowledge, there have been no reported studies dealing with the use of LIPUS to treat fractures or nonunion of the fingers.

Up to now in cases of nonunions, trauma surgeons have had to perform additional surgery with a more stable osteosynthesis and bone grafting. This can cause additional complications to the already pre-damaged soft tissue with further loss of function $[4,5]$. In this case we successfully used LIPUS, a non invasive treatment, to investigate its applicability in treating nonunion of fingers.

\section{Case presentation}

A 19-year-old Caucasian man was admitted to our emergency department with a critical ischemia of his right ring finger due to a crushing injury. His finger had been caught between a car and a car-jack while he was working as a mechanic. The first physical examination of the

\footnotetext{
* Correspondence: michaela1.huber@ukr.de

Department of Trauma, Plastic \& Hand Surgery, University Medical Center Regensburg, Regensburg, Germany
}

ring finger revealed an open wound of $3 \mathrm{~cm}$ on the dorsal side of the middle phalanx. Edges of the wound reached the ulnar and radial digital neurovascular bundle. The patient reported decreased sensibility of the end phalanx including painful range of motion (ROM) but without loss of function of all tendons. We found a restricted finger blood flow detected by nail bed compression in comparison with the uninjured fingers. An X-ray showed an undislocated transverse fracture of the middle phalanx (Figure 1a). The patient was immediately transferred to the operating room $(\mathrm{OR})$ where the wound was examined. Severe damage of the surrounding soft tissue was seen. Microscopic examination revealed no defect of the crushed vessels, the radial digital nerve was intact, but an epineural lesion was apparent for the ulnar digital nerve. A minimal osteosynthesis with two Kirschner-wires (Kwires) was performed. X-ray imaging showed an anatomical retention and fixation of the fracture (Figure 1b). The dorsal wound of the ring finger was cut out and sutured. The patient was discharged from the hospital on the fourth day without any sign of wound healing disturbance. The ring finger was immobilized with a finger splint including the proximal interphalangeal joint (PIP) and distal interphalangeal joint (DIP). 


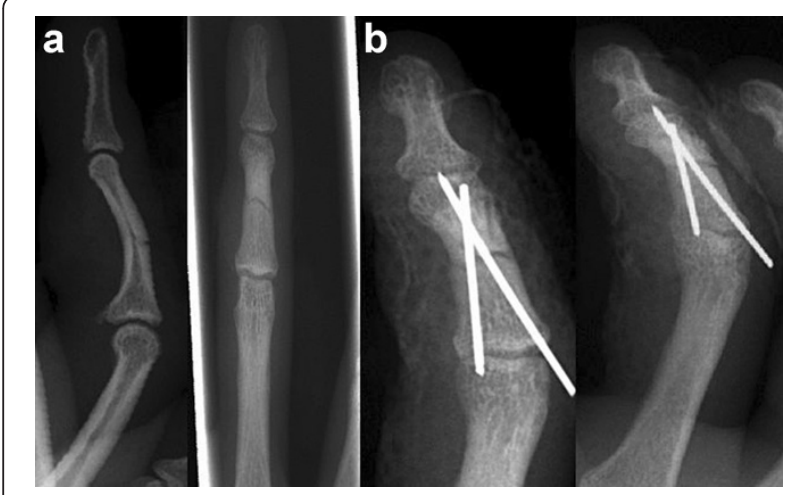

Figure 1 Initial X-ray after injury (a) and control X-ray after the osteosynthesis (b).

The patient was seen five months after initial treatment in our Out-Patient Clinic and reported painful moving of the right ring finger. The examination showed an instability of the middle phalanx with a passive lateral movement. Twenty degrees ulnar deviation of the ring finger with decreased ROM of the PIP joint (E/F 0-0-60 ) was apparent. In addition, the ring finger tended to cross over and overlap the adjacent finger when making a fist. The patient reported that ulna deviation of the ring finger started when K-wires had been removed by an office-based orthopedic surgeon two months after the initial surgery.

Since that time the finger was fixed again with a splint. He also complained about tingling, coolness and numbness of the injured finger. Since the X-ray showed a nonunion (Figure 2a) we started treatment with a LIPUS device (Fa. Melmak GmbH, Munich, Germany) three times daily for 20 minutes including the following parameter configuration:

Average intensity $\mathrm{I}=30 \mathrm{~mW} / \mathrm{cm}^{2}$ (SATA), ultrasound frequency $\mathrm{F}=1.5 \mathrm{MHz}$, signal impulse duration 200 microseconds, repetition rate $1 \mathrm{kHz}$, effective radiating area $3.88 \mathrm{~cm}^{2}$, temporal average power $117 \mathrm{~mW}$.

The ring finger was immobilized with a fitted personalized thermoplastic splint (Figure 3a) for six weeks. Six

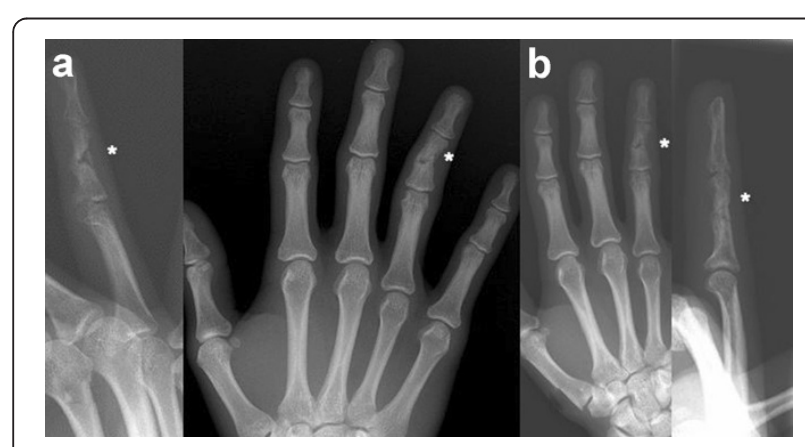

Figure 2 Control X-ray five months after initial operation (a); X-ray six weeks after LIPUS therapy (b). weeks after LIPUS treatment the patient reported to be without pain when moving his ring finger and clinical examination revealed a slight persistent ulna deviation of five degrees. The clinical examination showed a stable middle phalanx compared to the result six weeks previously. After four weeks of physiotherapy the ROM of the PIP joint was E/F $0-0-85^{\circ}$ and the fist closure was full (Figure $3 \mathrm{~b}$ ), except for the pre-existent limited ROM of the DIP-Joint (E/F 0-0-15 ). An X-ray confirmed fracture healing and calcification of the soft callus was clearly evident (Figure 2b).

\section{Discussion}

Severe injury of the fingers or the hand with a phalanx fracture requires rigid fixation with anatomical reduction to achieve appropriate bone healing. In addition, stable fracture fixation facilitates exercise very soon after surgical treatment avoiding restricted movement. The initial soft tissue damage, however, can limit the approach of osteosynthesis [4-6]. Using K-wires reduces the risk of further damage to the surrounding tissue while accepting less compression of the fracture that might cause nonunion. Second surgery is very common in nonunion fracture healing including bone graft and plate fixation [7] but second surgical intervention causes new or repeated soft tissue damage, leading to further loss of function. However, phalanx fracture fixation is needed in most cases and should be limited to a short period of time in order to achieve a ROM without restriction. Thus, low-intensity ultrasound seems to be an additional favorable tool for nonunion since it is effective and non-invasive [2,3]. Gebauer et al. reported in a randomized prospective trial that daily therapy of 20 minutes with low-intensity ultrasound achieved bone healing in $85 \%$ of cases [8] which was confirmed by other studies [9-12]. In a recently published Cochrane Review about ultrasound and shockwave therapy, in which 12 studies were evaluated, the authors concluded that the evidence of the analyzed clinical trials is insufficient to support the routine use of LIPUS [1]. In this case, there had been a three month splinting without

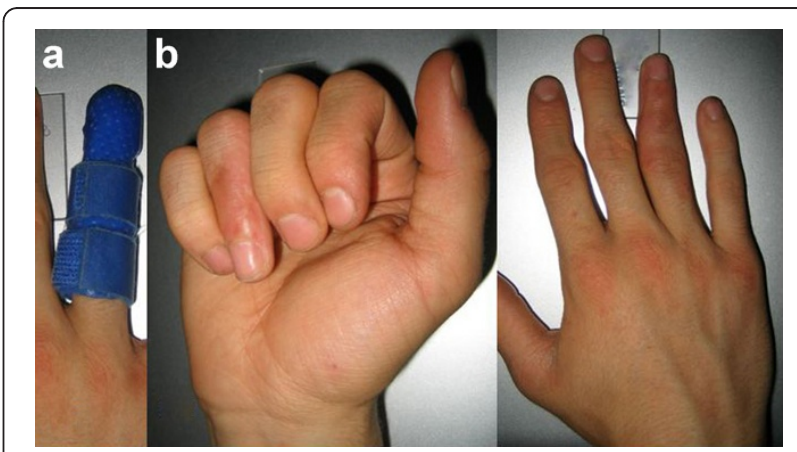

Figure 3 Personalized thermoplastic splint (a) and the functional result eight months after the initial trauma (b). 
success, so we decided to use LIPUS instead of bone grafting and osteosynthesis.

LIPUS is a pain free therapy performed daily at home by the patient with the possibility of avoiding a second surgical procedure. This out-patient treatment reduces the length of hospital stays for patients and the expenses of the health care system [13].

\section{Conclusion}

We report successful ultrasound treatment after inadequate bone healing with insufficient stability of the middle phalanx. The patient suffered from reduced ROM in the DIP and PIP joints. The patient also had an ulnar deviation associated with pain owing to the instability of the fracture. Based on this case report we suggest LIPUS as a possible approach for nonunion in finger injuries, however further clinical trials are necessary to confirm these preliminary findings.

\section{Consent}

Written informed consent was obtained from the patient for publication of this case report and any accompanying images. The written consent is available for review by the Editor-in-Chief of this journal.

\section{Competing interests}

The authors declare that they have no competing interests.

\section{Authors' contributions}

$\mathrm{MH}$ was the main author and performed the clinical assessment, follow-up and the bibliographic research. LP performed the clinical assessment, the surgery and the follow-up. SG was a major contributor in writing the manuscript. All authors have read and approved the final manuscript.

Received: 14 February 2012 Accepted: 18 July 2012

Published: 18 July 2012

\section{References}

1. Griffin XL, Costa ML, Parsons N, Smith N: Ultrasound and shockwave therapy for acute fractures in adults. Cochrane Database Syst Rev 2012 Feb15, 2:CD008579.

2. Siska PA, Gruen GS, Pape HC: External adjuncts to enhance fracture healing: what is the role of ultrasound? Injury 2008, 39:1095-1105.

3. Watanabe $Y$, Matsushita T, Bhandari M, Zdero R, Schemitsch EH: Ultrasound for fracture healing: current evidence. J Orthop Trauma 2010, 24:S56-S61.

4. Whitney TM, Lineaweaver WC, Buncke HJ, Nugent K: Clinical results of bony fixation methods in digital replantation. J Hand Surg 1990, 15:328-334.

5. Wolfe SW, Otchkiss RN, Pederson WC, Scott KH: The mangled upper extremity. In Greens Operative Handsurgery Vol 1. 6th edition. Philadelphia: Elsevier Churchill Livingstone; 2010:1603-1644.

6. Freeland $A E$, Lineaweaver $W C$, Lindley $S G$ : Fracture fixation in the mutilated hand. Hand Clin 2003, 19:51-61.

7. Ring D: Malunion and nonunion of the metacarpals and phalanges. Instr Course Lect 2006, 55:121-128.

8. Gebauer D, Mayr E, Orthner E, Ryaby JP: Low-intensity pulsed ultrasound: effects on nonunions. Ultrasound Med Biol 2005, 31:1391-1402.

9. Reher P: Elbeshir el-NI, Harvey W, Meghji S, Harris M: The stimulation of bone formation in vitro by therapeutic ultrasound. Ultrasound Med Biol 1997, 23:1251-1258

10. Malizos KN, Hantes ME, Protopappas V, Papachristos A: Low-intensity pulsed ultrasound for bone healing: an overview. Injury 2006, 37:S56-S62.
11. Nolte PA, van der Krans A, Patka P, Janssen IM, Ryaby JP, Albers GH: Lowintensity pulsed ultrasound in the treatment of nonunions. J Trauma 2001, 51:693-702.

12. Mayr $E$, Frankel $V$, Rüter $A$ : Ultrasound-an alternative healing method for nonunions? Arch Orthop Trauma Surg 2000, 120:1-8.

13. Heckman JD, Sarasohn-Kahn J: The economics of treating tibia fractures. The cost of delayed unions. Bull Hosp Jt Dis 1997, 56:63-72.

doi:10.1186/1752-1947-6-209

Cite this article as: Huber et al:: Successful treatment of nonunion in severe finger injury with low-intensity pulsed ultrasound (LIPUS): a case report. Journal of Medical Case Reports 2012 6:209.

\section{Submit your next manuscript to BioMed Central and take full advantage of:}

- Convenient online submission

- Thorough peer review

- No space constraints or color figure charges

- Immediate publication on acceptance

- Inclusion in PubMed, CAS, Scopus and Google Scholar

- Research which is freely available for redistribution 